\title{
The influence of stimulus properties on visual neglect
}

\author{
Richard Tegnér, Maria Levander
}

\begin{abstract}
Twenty five patients with right cerebral hemisphere damage and neglect participated in a series of bisection experiments. As expected, long lines were bisected to the right of true midpoint. By contrast, large circles and long white paper strips were bisected accurately, or with leftward errors. Small objects were less sensitive to stimulus properties: short lines and paper strips, and small circles, were bisected to the left of true midpoint, and these leftward errors were equally common as rightward errors with long lines. When asked to draw a perpendicular line of the same length as the presented horizontal line, patients overestimated the length of short lines but underestimated that of long lines. Presenting lines in near and far extrapersonal space selectively affected bisection of short lines. The results suggest that two opposing, independent mechanisms determine bisection performance in left neglect.
\end{abstract}

Line bisection is commonly used as a simple bedside test of unilateral neglect. ${ }^{12}$ In particular patients with right cerebral hemisphere damage and neglect transect lines to the right of geometric midpoint. In recent years, line bisection has become the most widely used tool in neglect research. The results are easy to quantify and can be subjected to statistical analysis even in single case studies. Despite this interest, little attention has been paid to stimulus properties. For example, nothing is known about how patients with unilateral neglect bisect objects other than lines. Part of our study is concerned with this issue. It originates from the informal observation that a patient with left unilateral neglect, who made large rightward errors when bisecting lines, was very accurate when asked to indicate the midpoint of objects such as tables and desks.

While it is generally accepted that the neglect syndrome is heterogeneous both between patients ${ }^{3}$ and between tasks, ${ }^{4}$ most studies tacitly assume that the behaviour of the individual patient on a particular task is shaped by a single "neglect" factor. This study describes a series of experiments that question this assumption. A starting point was the recent observation that patients with right cerebral hemisphere damage and left neglect transect very short lines $(25 \mathrm{~mm})$ to the left of the objective midpoint. ${ }^{5}$ Published stimulusresponse curves indeed give the impression that a single mechanism is operative since with decreasing line length rightward errors smoothly turn into leftward errors without any observable discontinuity. ${ }^{5-7}$

Bisection of short lines in a larger series of patients with right cerebral hemisphere

Table 1 Summary of clinical data

\begin{tabular}{|c|c|c|c|c|c|c|c|c|}
\hline \multirow[b]{2}{*}{ Patient } & \multirow[b]{2}{*}{ Age } & \multirow[b]{2}{*}{ Lesion } & \multirow[b]{2}{*}{$V F D$} & \multirow[b]{2}{*}{$P$} & \multirow[b]{2}{*}{$s$} & \multicolumn{3}{|c|}{ Neglect test } \\
\hline & & & & & & $R$ & $C A$ & $F C$ \\
\hline $\begin{array}{r}1 \\
2 \\
3 \\
4 \\
5 \\
6 \\
7 \\
8 \\
9 \\
10 \\
11 \\
12 \\
13 \\
14 \\
15 \\
16 \\
17 \\
18 \\
19 \\
20 \\
21 \\
22 \\
23 \\
24 \\
25\end{array}$ & $\begin{array}{l}45, M \\
74, M \\
82, \mathrm{~F} \\
76, M \\
78, M \\
67, M \\
69, M \\
57, \mathrm{~F} \\
61, M \\
77, M \\
65, M \\
67, M \\
51, \mathrm{~F} \\
72, M \\
62, \mathrm{~F} \\
50, \mathrm{~F} \\
49, M \\
61, M \\
75, \mathrm{~F} \\
82, M \\
20, \mathrm{~F} \\
88, M \\
54, M \\
74, M \\
67, M\end{array}$ & 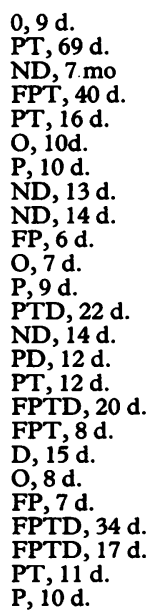 & $\begin{array}{l}+ \\
+ \\
- \\
+ \\
+ \\
+ \\
+ \\
+ \\
+ \\
+ \\
+ \\
+ \\
+ \\
+ \\
+ \\
+ \\
+ \\
+ \\
+ \\
+ \\
+ \\
+ \\
+ \\
+\end{array}$ & $\begin{array}{l}- \\
+ \\
+ \\
+ \\
+ \\
+ \\
- \\
+ \\
+ \\
+ \\
+ \\
+ \\
+ \\
+ \\
+ \\
+ \\
+ \\
+ \\
+ \\
+ \\
+ \\
+ \\
+ \\
+\end{array}$ & $\begin{array}{l}- \\
+ \\
+ \\
+ \\
+ \\
+ \\
+ \\
+ \\
+ \\
+ \\
+ \\
+ \\
+ \\
+ \\
+ \\
+ \\
+ \\
+ \\
+ \\
+ \\
+ \\
+ \\
+\end{array}$ & $\begin{array}{l}9 / 10 \\
10 / 10 \\
0 / 10 \\
7 / 10 \\
2 / 10 \\
\text { ND } \\
7 / 10 \\
0 / 10 \\
5 / 10 \\
8 / 10 \\
10 / 10 \\
10 / 10 \\
7 / 10 \\
0 / 10 \\
\text { ND } \\
10 / 10 \\
0 / 10 \\
0 / 10 \\
6 / 10 \\
0 / 10 \\
6 / 10 \\
\text { ND } \\
\text { ND } \\
\text { ND } \\
2 / 10\end{array}$ & $\begin{array}{r}53 / 60 \\
34 / 40 \\
22 / 40 \\
26 / 40 \\
0 / 40 \\
21 / 40 \\
0 / 40 \\
10 / 40 \\
11 / 60 \\
32 / 40 \\
49 / 60 \\
30 / 40 \\
55 / 60 \\
52 / 60 \\
34 / 60 \\
49 / 60 \\
34 / 60 \\
53 / 60 \\
54 / 60 \\
22 / 40 \\
23 / 60 \\
36 / 40 \\
59 / 60 \\
31 / 60 \\
8 / 40\end{array}$ & $\begin{array}{l}+ \\
+ \\
\text { ND } \\
+ \\
+ \\
+ \\
+ \\
+ \\
+ \\
+ \\
+ \\
+ \\
+ \\
\text { ND } \\
+ \\
+ \\
+ \\
+ \\
+ \\
+ \\
+ \\
+ \\
+ \\
+ \\
+\end{array}$ \\
\hline
\end{tabular}

Department of Neurology, Karolinska Hospital, Stockholm, Sweden R Tegnér $M$ Levander

Correspondence to: Dr Tegnér, Department of Neurology, Karolinska Hospital, 10401 Stockholm Sweden

Received 19 November 1990 and in revised form 11 February 1991.

Accepted 21 February 1991
$F=$ frontal $P=$ parietal $;=$ temporal $O=$ occipital $; D=$ deep VFD = visual field defect $P=$ hemiparesis; $S=$ sensory $F=$ frontal; $P=$ parietal $T=$ temporal $;=$ occipital $D=$ deep; $V F D=$ visual field defect; $P=$ hemiparesis; $S=$ sensory
loss $R=$ number of errors on reading test $C A=$ number of omissions on cancellation test $F C=$ left-sided omissions on figure copying; ND = not done. 
damage and neglect is also described, since previously only a few single cases have been reported.

\section{Materials and methods SUBJECTS}

We examined a consecutive series of 25 right handed patients with unilateral neglect after right cerebrovascular lesions. Their clinical data are summarised in table 1 . There were seven women and 18 men with a mean age of $64 \cdot 7$ years (SD 14.4 years, range $22-82$ years). All patients had signs of unilateral neglect on one or more tests: a modified version of Albert's line cancellation $\operatorname{task}^{8}$ or a random letter cancellation task, ${ }^{9}$ a line bisection task, reading, and figure copying. Line bisection was assessed by presenting $2 \mathrm{~mm}$ wide black lines, ranging in length from $25-200 \mathrm{~mm}$, on separate sheets of white paper; data from $200 \mathrm{~mm}$ lines are shown in table 1 . Neglect dyslexia was tested with 10 sentences of four words each, presented one at a time; the number of sentences with neglect omissions is shown in table 1. Age of lesion refers to time of first line bisection test, while other experiments were performed up to three months later.

Patients with a history of previous stroke, or CT scan evidence of multiple lesions were excluded.

In the experiments described below, participating patients are referred to by their numbers in table 1 .

The control groups comprised 13 patients with right brain damage (six women, seven men) and 14 patients with left brain damage (six women, eight men) without neglect, and 10 subjects (five women, five men) without neurological disease. Their mean (SD) ages were $63.1(9.7)$ years, $63.2(10 \cdot 1)$ years, and $55.6(10.4)$ years, respectively. They constitute the RBD-, LBD-, and NC groups, respectively. Controls with brain damage had distinct neurological impairments secondary to cerebrovascular lesions. They were examined five to 23 days after stroke. No attempt was made to match the groups for lesion size.

\section{METHODS}

Subjects were asked to bisect horizontal lines, rectangles, circles, and strips of white paper. Stimuli had lengths (diameters) of $25 \mathrm{~mm}$, $100 \mathrm{~mm}$, and $200 \mathrm{~mm}$. They were presented separately and always positioned on the desk in front of the subject so that the objective midpoint lay in the sagittal midplane of the subject's trunk. Deviations from objective midpoint were measured to the nearest half millimetre; a positive sign denotes rightward deviation.

Task 1. Line bisection

Methods Lines, $2 \mathrm{~mm}$ wide, were drawn in black ink in the middle of white sheets of A4 paper. The line bisection data in table 2 always refer to the first administered line bisection test, even if the test session included
Table 2 Line bisection data

\begin{tabular}{|c|c|c|c|}
\hline Patient & $25 \mathrm{~mm}$ & $100 \mathrm{~mm}$ & $200 \mathrm{~mm}$ \\
\hline $\begin{array}{l}1 \\
2 \\
3 \\
4 \\
5 \\
6 \\
7 \\
8^{\star} \\
9 \\
10 \\
11 \\
12 \\
13 \\
14 \\
15 \\
16 \\
17 \\
18 \\
19 \\
20 \\
21 \\
22^{\star} \\
23 \\
24 \\
25\end{array}$ & $\begin{array}{r}-6.6 \\
-4.8 \\
-2.7 \\
-2.8 \\
-0.1 \\
-0.5 \\
-3.1 \\
-1.0 \\
0.9 \\
-2.7 \\
-1.4 \\
-1.8 \\
-1.2 \\
-0.7 \\
-1.1 \\
-0.6 \\
-2.5 \\
-1.7 \\
-4.7 \\
-4.3 \\
-1.6 \\
-7.0 \\
-2.8 \\
-2.3 \\
-1.8\end{array}$ & $\begin{array}{r}22.7 \\
29.6 \\
14.0 \\
6.8 \\
6.3 \\
34.0 \\
28.2 \\
-4.0 \\
10.9 \\
2.2 \\
10.6 \\
1.5 \\
N D \\
3.8 \\
13.6 \\
-1.9 \\
0.2 \\
1.0 \\
1.1 \\
21.0 \\
2.3 \\
6.0 \\
-\quad 1.3 \\
19.4 \\
6.8\end{array}$ & $\begin{array}{r}54 \cdot 2 \\
74 \cdot 2 \\
32 \cdot 2 \\
28 \cdot 1 \\
29 \cdot 3 \\
60 \cdot 4 \\
58 \cdot 3 \\
23 \cdot 0 \\
21 \cdot 4 \\
10 \cdot 8 \\
39 \cdot 6 \\
20 \cdot 7 \\
2 \cdot 6 \\
12 \cdot 5 \\
50 \cdot 2 \\
2 \cdot 6 \\
7 \cdot 3 \\
8 \cdot 6 \\
12 \cdot 2 \\
36 \cdot 4 \\
3 \cdot 2 \\
47 \cdot 0 \\
5 \cdot 0 \\
54 \cdot 7 \\
13 \cdot 6\end{array}$ \\
\hline $\begin{array}{l}\text { Mean (SD) } \\
\text { RBD- } \\
\text { (range) } \\
\text { LBD- } \\
\text { (range) } \\
\text { NC } \\
\text { (range) }\end{array}$ & $\begin{array}{c}-2.43(1.82) \\
0.19(0.76) \\
-1->1.8 \\
0.05(0.70) \\
-1->1.5 \\
0.20(0.41) \\
-0.4->0.9\end{array}$ & $\begin{array}{l}9.78(10.82) \\
0.07(1.48) \\
-2->3.3 \\
-0.81(2.75) \\
-4.5->5.2 \\
-0.38(1.13) \\
-2.5->1.4\end{array}$ & $\begin{array}{l}28.33(21.36) \\
-0.22(4.03) \\
-8->5.5 \\
-3.30(5.18) \\
-14->5.8 \\
-1.60(2.66) \\
-4.5->3.5\end{array}$ \\
\hline
\end{tabular}

Deviations (in $\mathrm{mm}$ ) from objective midpoint; positive sign denotes rightward error. ${ }^{\star}$ Only one line of each length.

bisection of other objects, see below. Some patients only took part in a line bisection test where 5-10 lines of each length were presented in random order (two neglect patients, two RBD-, and two LBD- patients only bisected one line of each length)

Results Table 2 shows that 24 of 25 patients with right brain damage and neglect bisected $25 \mathrm{~mm}$ lines to the left of objective midpoint. The group mean error of $-2.43 \mathrm{~mm}$ deviates significantly from the objective midpoint $\left(t_{24}=6.68, p<0.001\right)$. Furthermore, 19 of 25 patients with neglect bisected $25 \mathrm{~mm}$ lines outside the range of patients with brain damage without neglect; the corresponding figure for $200 \mathrm{~mm}$ lines was 21 of 25 patients and thus of the same magnitude.

Leftward errors with short lines were not related to the presence of a visual field defect, since the four patients with normal visual fields made equally large leftward errors (mean $=-2.55 \mathrm{~mm}$ ).

As expected, the magnitude of the errors with $100 \mathrm{~mm}$ and $200 \mathrm{~mm}$ lines correlated significantly (Spearman's rank correlation, rho $=0.86, p<0.01)$. However, it was not the case that large leftward errors with $25 \mathrm{~mm}$ lines coincided with large rightward errors with longer lines (Spearman's rank correlation; $100 \mathrm{~mm}$ lines: rho $=-0.21,200 \mathrm{~mm}$ lines; rho $=-0 \cdot 26$, both $\mathrm{p}>0 \cdot 10$ ).

Patient 1 is of particular interest. On a few occasions, he actually placed the mark outside the left end of the $25 \mathrm{~mm}$ line, see fig 1. This was not due to disturbed motility since he could accurately draw a circle around a small letter or point to a small dot. He spontaneously remarked that he found the task very difficult because, while long lines appeared to become progressively thinner leftwards, short 
Figure 1 Examples of line bisection from patient 1. Top $100 \mathrm{~mm}$ line with rightward error. Bottom $25 \mathrm{~mm}$ line with subjective midpoint outside the

presented line.

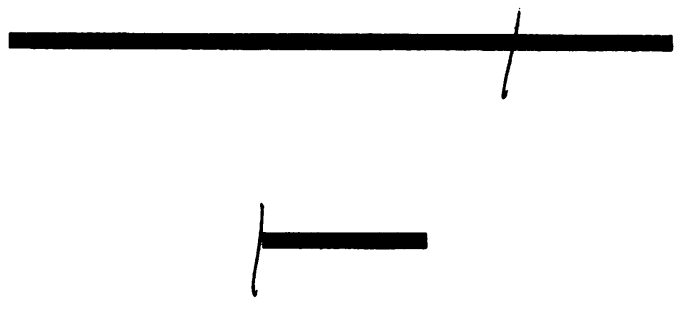

lines instead appeared to have a leftward greyish elongation.

\section{Task 2. Bisection of other objects}

Methods Only patients with right brain damage and neglect participated in these experiments. Circles were outline drawings in black ink positioned in the middle of white sheets of A3 paper. Letraset strips, $2 \mathrm{~mm}$ wide, were used to make white lines on black sheets of A4 paper. White paper strips had height $=0.5 \times$ length; they were presented directly on the mat white desk top. Black filled rectangles had height $=0.25 \times$, and $0.5 \times$ length, and were mounted on white sheets of A4 paper. In all experiments ten stimuli of each kind and length (diameter) were used. Black lines were always used mixed with another stimulus type and the stimuli then presented in a fixed random order.

Results Two patients bisected both black filled rectangles and white lines on black paper. Table 3 shows that performance was the same with these stimuli as with ordinary black lines (paired $t$ tests, all $\mathrm{p}>0 \cdot 10$ ).

In contrast, major differences were observed when patients bisected white paper strips (table 4). Large rightward errors with $100 \mathrm{~mm}$ and $200 \mathrm{~mm}$ lines were reduced in all but one patient (5), and in six patients became leftward errors. The group mean values did not significantly deviate from the objective midpoint with $100 \mathrm{~mm}$ and $200 \mathrm{~mm}$ paper strips $\left(100 \mathrm{~mm}, t_{9}=0.14, \quad p>0.10 ; 200 \mathrm{~mm}\right.$ : $\left.\mathrm{t}_{9}=1 \cdot 32, \mathrm{p}>0 \cdot 10\right)$. By contrast, no dissociation was seen with $25 \mathrm{~mm}$ stimuli: the magnitude of the leftward errors was the same with lines and paper strips and group mean values were significantly to the left of objective

Table 3 Bisection of black and white lines and black filled rectangles

\begin{tabular}{llll}
\hline Patient & $25 \mathrm{~mm}$ & $100 \mathrm{~mm}$ & $200 \mathrm{~mm}$ \\
\hline $\begin{array}{l}1 \\
\text { black lines } \\
\text { white lines }\end{array}$ & $-4.6(1.95)$ & $\begin{array}{l}14.8(8.19) \\
17.4(6.75)\end{array}$ & $\begin{array}{l}37.7(17.26) \\
41.6(15.74)\end{array}$ \\
$\begin{array}{l}\text { rectangles } \\
\text { black lines } \\
\text { height }=\end{array}$ & $-4.7(0.88)$ & $31.1(4.82)$ & $62.8(9.55)$ \\
$\begin{array}{l}\times 0.25 \\
\text { height }=\end{array}$ & $-4.8(1.67)$ & $33.1(6.15)$ & $66.2(11.99)$ \\
$\quad \times 0.50$ & $-4.5(1.91)$ & $27.3(7.44)$ & $56.8(14.61)$ \\
$\begin{array}{l}2 \\
\text { black lines } \\
\text { white lines }\end{array}$ & $-3.4(2.11)$ & $7.4(3.98)$ & $27.5(11.62)$ \\
$\begin{array}{l}\text { rectangles } \\
\text { black lines } \\
\text { height }=\end{array}$ & $-2.6(1.62)$ & $30.1(4.17)$ & $57.8(9.20)$ \\
$\quad \times 0.25$ & $-1.8(1.32)$ & $27.7(4.79)$ & $55.5(5.95)$ \\
$\begin{array}{l}\text { height }= \\
\times 0.50\end{array}$ & $-2.3(1.06)$ & $32.4(6.10)$ & $60.9(14.00)$ \\
\hline
\end{tabular}

Mean (SD); deviations (in $\mathrm{mm}$ ) from objective midpoint; positive sign denotes rightward error. midpoint (lines: $t_{9}=4 \cdot 31$; paper strips: $\mathrm{t}_{9}=3.88$; both $\mathrm{p}<0.01$ ).

The same pattern was observed in two patients who bisected circles (table 5, fig 2). They made large rightward errors with $100 \mathrm{~mm}$ and $200 \mathrm{~mm}$ lines while they more accurately bisected circles of the same dimensions. By contrast, the leftward error was the same with $25 \mathrm{~mm}$ lines and circles.

Task 3. Drawing a perpendicular line

Subjects were asked to draw a line perpendicular to, and of the same length as, the stimulus line. The task was chosen because it provides an independent measure of how patients estimate line length and it also eliminates a possible influence of directional hypokinesia, that is, an impaired ability to initiate or execute movements into or towards contralateral hemispace. ${ }^{10}$

Methods Five lines of each length were drawn on separate A3 sheets of paper and presented in pseudorandom order. All subjects, except the patients with left brain damage, were asked to use their right hand and to start drawing at the right endpoint of the presented line. Patients with left brain damage used their left hand and started drawing at the left endpoint.

Results These are shown in table 6 and an example is shown in fig 3. With $200 \mathrm{~mm}$ lines subjects drew lines that were shorter than the presented ones ( $t$ tests, all $\mathrm{p}<0.05$ ); this is the well known horizontal-vertical illusion. There was no significant difference between controls and neglect patients despite the obvious outliers in the neglect group (Kruskal-Wallis $\mathrm{T}=4.96, \mathrm{df}=3, \mathrm{p}>0 \cdot 10$ ). With $25 \mathrm{~mm}$ lines neglect patients differed significantly from controls (Kruskal-Wallis $T=22.04$, $\mathrm{df}=3, \mathrm{p}<0.001)$. Neglect patients drew lines that.were significantly longer than those presented $\left(t_{9}=3.43, p<0.01\right)$, while controls drew lines that were significantly shorter $(t$ tests, all $\mathrm{p}<0.01$ ).

\section{Task 4. Line bisection through a reversed} binocular

The experiment was carried out to compare how patients bisect long and short lines presented in far extrapersonal space.

Methods Subjects were asked to bisect lines positioned on the desk in front of them while looking through a reversed binocular, that is, "the wrong way". The binocular $(10 \times 25$, Field $5.51 / 2$ ) was prefocussed for distances of $>100 \mathrm{~m}$. When viewed through it the wrong way, stimuli are perceived as if they were positioned $36 \mathrm{~m}$ in front of the viewer with preserved visual angle. The two conditions (with and without reversed binocular) were presented in an ABAB design starting without binocular. Patients bisected a total of 20 lines (controls 10) for each condition and line length. This is a difficult task and most patients with neglect could not simultaneously hold the binocular and bisect a line or they just could not find the lines. Only two patients with neglect were therefore adequately examined.

Results Table 7 shows that binocular view selectively altered performance with $25 \mathrm{~mm}$ 
Table 4 Bisection of black lines and white paper strips

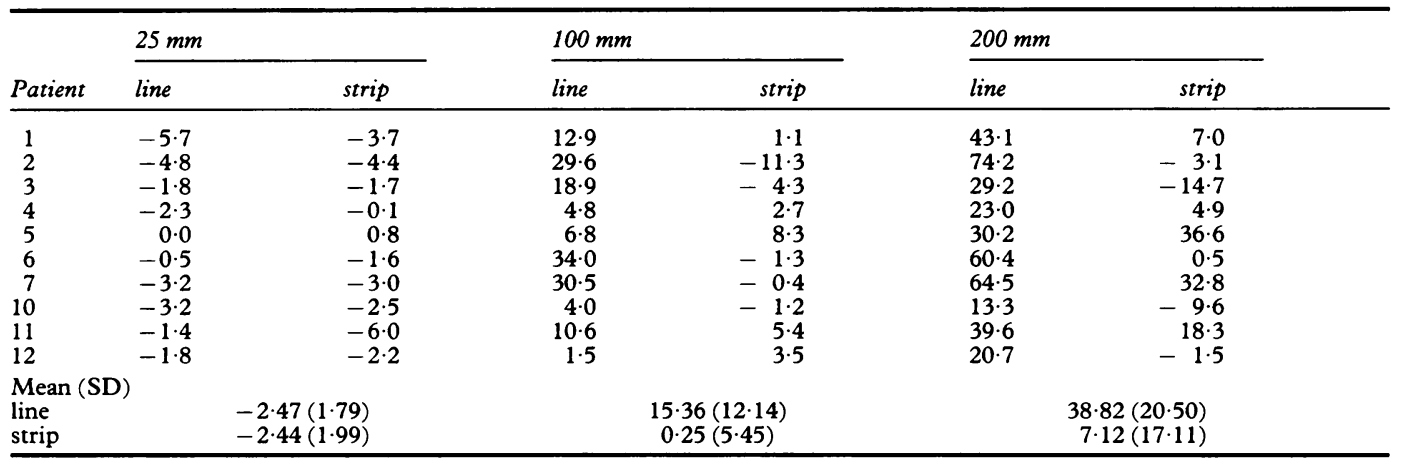

Deviations (in $\mathrm{mm}$ ) from objective midpoint; positive sign denotes rightward error.

Table 5 Bisection of lines and circles

\begin{tabular}{lcrc}
\hline Patient & $25 \mathrm{~mm}$ & $100 \mathrm{~mm}$ & $200 \mathrm{~mm}$ \\
\hline 2 & & & \\
line & $-5.0(1.1)$ & $22.0(3.3)$ & $46.7(11.1)$ \\
circle & $-4.4(1.0)$ & $-2.2(2.4)$ & $2.3(8.3)$ \\
25 & & & \\
line & $-1.8(1.2)$ & $6.8(0.9)$ & $13.6(3.8)$ \\
circle & $-1.3(0.7)$ & $1.0(2.6)$ & $1.1(3.6)$ \\
\hline
\end{tabular}

Mean (SD); deviations (in $\mathrm{mm}$ ) from objective midpoint; positive sign denotes rightward error.

lines so that leftward errors were shifted into rightward errors (paired $t$ tests for $25 \mathrm{~mm}$ lines, $1: t_{19}=14.2 ; 2: t_{19}=8.7$, both $p<0.001$ ).

\section{Discussion}

There are previous single-case reports of patients with right brain damage and neglect who make leftward errors when they bisect short lines. ${ }^{5-7}$ Our results establish that this behaviour is just as common as the more well known rightward errors with long lines.

Stimulus properties to a large extent determined bisection performance. Near normal accuracy was found with 100-200 mm outline drawings of circles and white paper strips presented on a white mat desk top. Bisection of filled black rectangles and lines, on the other hand, was abnormal both when lines were drawn in black on white and in white on black. Necessary conditions for rightward

Figure 2 Bisection of 25 and $200 \mathrm{~mm}$ lines and circles. Example from patient 25.

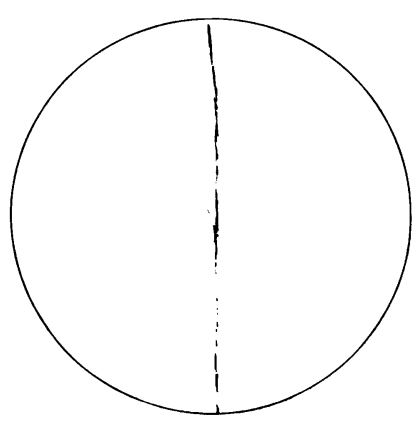

Figure 3 Patients were asked to draw a perpendicular of the same length as the presented horizontal line. Left $25 \mathrm{~mm}$ line. Right $200 \mathrm{~mm}$ line. Example from patient 2.

Table 7 Line bisection through a reversed binocular

\begin{tabular}{|c|c|c|c|}
\hline Patient & Normal view & & Binocular view \\
\hline $\begin{array}{l}1 \\
25 \mathrm{~mm} \\
100 \mathrm{~mm} \\
200 \mathrm{~mm}\end{array}$ & $\begin{array}{r}-7 \cdot 0(1 \cdot 8) \\
23.1(4.5) \\
57.4(11.4)\end{array}$ & $\begin{array}{l}\star \star \star \\
N S\end{array}$ & $\begin{array}{c}2 \cdot 5(2 \cdot 1) \\
27 \cdot 6(9 \cdot 5) \\
51 \cdot 6(20 \cdot 6)\end{array}$ \\
\hline $\begin{array}{l}2 \\
25 \mathrm{~mm} \\
100 \mathrm{~mm} \\
200 \mathrm{~mm}\end{array}$ & $\begin{array}{r}3.9(1.7) \\
6.5(2.7) \\
30.2(5.9)\end{array}$ & $\begin{array}{l}\star \star \star \\
N S \\
N S\end{array}$ & $\begin{array}{c}2 \cdot 2(2 \cdot 1) \\
9 \cdot 0(8 \cdot 6) \\
29 \cdot 9(12 \cdot 7)\end{array}$ \\
\hline $\begin{array}{l}\mathrm{NC} \\
25 \mathrm{~mm} \\
\text { (range) } \\
100 \mathrm{~mm} \\
\text { (range) } \\
200 \mathrm{~mm} \\
\text { (range) }\end{array}$ & $\begin{aligned} & 0.20(0.41) \\
- & 0.4->0.9 \\
- & 0.38(1.13) \\
- & 2.5->1.4 \\
- & 1.60(2.66) \\
- & 4.5->3.5\end{aligned}$ & $\begin{array}{l}\text { NS } \\
\text { NS } \\
\text { NS }\end{array}$ & $\begin{array}{r}-0.15(1.29) \\
-1.8->1.6 \\
1.05(4.16) \\
-6.2->7.2 \\
-2.30(5.81) \\
-9.3->6.8\end{array}$ \\
\hline
\end{tabular}

Mean (SD); deviations (in $\mathrm{mm}$ ) from objective midpoint; positive sign denotes rightward error; ${ }^{\star \star}=\mathrm{p}<0.001 ; \mathrm{NS}=$ not significant.

errors to occur therefore appears to be: 1) that there is sufficient contrast between figure and ground, and 2) that stimuli are pointed or have sharp edges. Lines and rectangles, but not 
circles, have a distinct right endpoint that may capture the attention of neglect patients or from which they cannot disengage their attention. ${ }^{11} 12$

An important conclusion is that theories that try to explain neglect behaviour on line bisection have to take stimulus properties into account. For example, Marshall and Halligan ${ }^{7}$ proposed that line bisection is equivalent to comparing the two halves of the line, and that neglect patients have an increased "zone of indifference" where the two lines appear to have the same length. With longer lines patients with neglect approach the zone from the right, and they make rightward errors, but with short lines in central vision they approach the zone from the left, that is, they use a normal leftright scanning strategy, and accordingly they make leftward errors. Their explanation is difficult to reconcile with our results since it predicts that absolute errors should be as large with circles and paper strips as with black lines.

A series of independent experiments showed that bisection of large and small objects is determined by different mechanisms in patients with neglect. First, no correlation was found between the magnitudes of the leftward errors with short lines and the rightward errors with longer lines. Second, only rightward errors with large objects were sensitive to stimulus properties. Third, the results from task 3 indicate that neglect patients perceive short lines as longer and long lines as shorter than they actually are. Fourth, presenting lines through a reversed binocular selectively influenced bisection of short lines. The results therefore suggest that bisection performance in patients with neglect is the outcome of two independent mechanisms with opposing effects, one pushing to the left and the other to the right.

It could be argued that the mechanisms are not only independent but also non-interactive: the left-pushing mechanism is operative with small objects in central vision and the rightpushing mechanism with larger objects in peripheral vision. Such an interpretation is in line with previous data that neglect in peripheral vision is found both in patients with right brain damage and after those with left brain damage while neglect in central vision is found only in patients with right brain damage. ${ }^{13}$ An interaction between the two opposing mechanisms seems, however, more likely since several patients made large leftward errors with 200 mm paper strips and large rightward errors with $200 \mathrm{~mm}$ black lines.

As for details of the mechanisms, the rightpushing mechanism is more easily envisaged as a hyper-attraction to the rightmost part of certain stimuli. ${ }^{11}$ Circles, due to their shape, and paper strips, due to lack of contrast, would not as easily evoke this mechanism as lines with the consequence that a left-pushing mechanism takes precedence (for a criticism of this attentional explanation, see Bisiach et al $^{3}$ ).

Perceptual completion is a possible candidate for the left-pushing mechanism. Since the report by Warrington ${ }^{14}$ of perceptual completion across hemianopic field defects, several studies have used this phenomenon to explain line bisection in neglect.

Eye movement recordings have shown that hemianopic patients with left neglect bisect 150-200 mm lines at the fixation point. ${ }^{15}$ The authors proposed that the damaged right hemisphere uses the right half of the line projected to the left hemisphere and by representational completion makes an image of a line that is symmetrical with respect to the fixation point.

In the original paper on leftward errors with short lines, the authors suggested that their patient had an attentional boundary slightly to the left of objective midpoint and that the patient completed short lines up to this boundary. ${ }^{5}$ While later studies have refuted the existence of an attentional boundary, ${ }^{616}$ perceptual completion remains a possible mechanism.

Indeed, some of our results suggest that completion may be of importance. First on a few occasions patient 1 bisected short lines outside the left endpoint, and he spontaneously remarked that these lines appeared to have a greyish elongation on their left side. The patient of Marshall and Halligan similarly transected $25 \mathrm{~mm}$ lines up to $18 \mathrm{~mm}$ to the left of objective midpoint. ${ }^{5}$ Second, only patients with right brain damage and neglect consistently drew perpendicular lines that were longer than the presented $25 \mathrm{~mm}$ lines; we have no reasonable explanation other than that presented short lines were perceived as longer than they actually were.

A major obstacle to this explanation is that patients made leftward errors also with small circles which we fail to envisage as due to perceptual completion. It could be argued that we are dealing here with a phenomenon that is akin to perceptual completion but still distinct from it. This is suggested by the comment of patient 1 about a greyish elongation on the left side of short lines, something which is not really the same as perceptual completion which "refers to seeing a figure as complete when part of it falls in a blind area of the visual field". 15

Finally, in Task 4 lines for bisecting were presented through a reversed binocular. The purpose was to study if behaviour with long and short lines is dissociable. As pointed out by Dr Vallar (personal communication), the experiment also has a bearing on the question of whether visual neglect can occur independently in near and far extrapersonal space. No dissociation was found when the Wundt-Jastrow area illusion test was used. ${ }^{17}$ This is a purely sensory task, and the authors concluded that "the presence of a motor response may be necessary to show behavioural dissociations between different parts of extrapersonal space". Task 4 requires a motor response and a dissociation was indeed found when lines were presented in near and far extrapersonal space. The interpretation is, however, complicated by the stimulusresponse incompatibility, that is, lines were perceived in near or far extrapersonal space but the motor response was always performed in near extrapersonal space. 
The research was supported by the Swedish Council for Planning and Coordination of Research (Dnr 890258:2), the Swedish Medical Research Council (Dnr K90-19P-09318$01 A$, and the Swedish Society for Prevention of Stroke. We thank Staffan Ekblom, Institute of Actuarial Mathematics and Mathematical Statistics, University of Stockholm, for statistical advice, and Göran Manneberg, Institute of Optical Research, The Royal Institute of Technology, Stockholm, for calculating the imaging system of Task 4 .

1 Bisiach E, Capitani E, Colombo A, Spinnler H. Halving a horizontal segment: a study on hemisphere-damaged patients with cerebral focal lesions. Archives Suisses de Neurologie, Neurochirurgie et de Psychiatrie 1976;2: 199-206.

2 Schenkenberg T, Bradford DC, Ajax ET. Line bisection and unilateral visual neglect in patients with neurological impairment. Neurology 1985;30:509-17.

3 Bisiach E, Bulgarelli C, Sterzi R, Vallar G. Line bisection and cognitive plasticity of unilateral neglect of space. Brain and Cognition 1983;2:32-8.

4 Friedland R, Weinstein E. Hemi-inattention and hemispace specialisation: introduction and historical review. $A d v$ Neurol 1977;18:1-31

5 Halligan PW, Marshall JC. How long is a piece of string? A study of line bisection in a case of visual neglect. Cortex study of line bisec
$1988 ; 24: 321-8$.

6 Tegnér R, Caneman G, Levander M. Apparent right neglect in patients with left visual neglect. Cortex 1990;26:455-8. 7 Marshall JC, Halligan PW. When right goes left: an investigation of line bisection in a case of visual neglect. Cortex 1989;25:503-15.

8 Albert ML. A simple test of visual neglect. Neurology 1973;23:658-64.

9 Mesulam M-M. Attention, confusional states, and neglect. In: Mesulam M-M, ed. Principles of behavioral neurology. Philadelphia: FA Davis, 1985:125-68.

10 Watson RT, Miller BD, Heilman KM. Nonsensory neglect. Ann Neurol 1978;3:505-8.

11 Mark VW, Kooistra CA, Heilman KM. Hemispatial neglect affected by non-neglected stimuli. Neurology 1988;

12 Posner MI, Walker JA, Friedrich FA, Rafal RD. Effects of parietal injury on covert orienting of attention. $J$ Neurosci 1984;4:1863-74.

13 Gainotti G, D'Erme P, Monteleone D, Silveri MC Mechanisms of unilateral spatial neglect in relation to laterality of cerebral lesions. Brain 1986;109:599-612.

14 Warrington EK. The completion of visual forms across hemianopic field defects. J Neurol, Neurosurg, Psychiatry 1962;25:208-17.

15 Ishiai S, Furukawa T, Tsukagoshi H. Visuospatial processes of line bisection and the mechanisms underlying unilateral spatial neglect. Brain 1989;112:1485-502.

16 Halligan PW, Marshall JC. Line bisection in visuo-spatial neglect: disproof of a conjecture. Cortex 1989;25:517-21.

17 Pizzamiglio L, Cappa S, Vallar G, et al. Visual neglect for far and near extra-personal space in humans. Cortex 1989; 25:471-7. 